\title{
Copper alloy production in the Warring States period (475-221 BCE) of the Shu state: a metallurgical study on copper alloy objects of the Baishoulu cemetery in Chengdu, China
}

\author{
Haichao $\mathrm{Li}^{1,2}$, Zhiqiang Zuo ${ }^{3}$, Jianfeng Cui ${ }^{4}$, Jianbo Tian ${ }^{3}$, Yingdong Yang ${ }^{3}$, Li Yi ${ }^{3}$, Zhiqing Zhou ${ }^{3}$
} and Jianan Fan ${ }^{2 *}$ (1)

\begin{abstract}
Many bronze objects were unearthed in the capital of the Shu state in present-day Chengdu. However, only a few metallurgical studies have been carried out on those objects. This research attempts to study the alloy techniques and possible ore sources of 28 bronze objects recently excavated from the Baishoulu cemetery in Chengdu. Elemental composition and lead isotope ratios were measured, and metallographic observations were conducted. The results indicate that most objects were copper-tin-lead alloys with variable tin and lead content. The samples showed evidence of casting, as well as cold working and annealing techniques. The lead isotope data indicate that multiple lead sources were used in Baishoulu; however, the exact number is not yet known. Most of the lead sources in Baishoulu are the same as those in Zeng state bronze and Chu state bronze. In addition, some of the bronzes came from sources that were widely used in the Central Plains and surrounding regions. This new information aids in understanding the cultural interactions between Shu and other states. Moreover, some bronzes might have used local lead sources. Copper and tin sources were difficult to determine; however, the different trace elemental patterns between Baishoulu and Bayilu bronzes indicate different copper and tin sources might be used. Additionally, copper and lead may originate from different sources in the Shu state. Systematic data are necessary to disclose a possible metal source exchange network involving the Shu state in the Warring States period.
\end{abstract}

Keyword: Shu state, Chengdu, Bronze production, Lead isotope, Elemental composition

\section{Introduction}

During the Warring States period in China (475-221 $\mathrm{BCE}$ ), many states were distributed throughout the country; frequent warfare, along with the establishment of various alliances, created complex relationships among them $[1,2]$. Shu was one such ancient state, and while scholars contest the exact date of its establishment, it is believed to have existed during the Warring States

\footnotetext{
*Correspondence: fanjianan1989@126.com

${ }^{2}$ Department of Archaeology, School of History and Culture, Sichuan University, Chengdu 610065, China

Full list of author information is available at the end of the article
}

period. The Shu state reached its ultimate demise, however, when conquered by the Qin state in 316 BCE [3-5]. One unique feature of the Shu state is its isolated and unique cultural region $[6,7]$. The bronze artefacts of the Shu state indeed reveal their uniqueness. The Shu state bronzes centre mostly on 3 types of weapons: swords and spears in the shape of a willow's leaf, and triangle daggeraxes which were rarely seen outside the Shu state [8-10].

The most important question intriguing scholars is the relationship between this isolated state and other states outside the Sichuan Basin in the Warring States period. Is bronze production in the Shu state related to other states, or completely independent of them? Is there any
Springer Open

(c) The Author(s) 2020. This article is licensed under a Creative Commons Attribution 4.0 International License, which permits use, sharing adaptation, distribution and reproduction in any medium or format, as long as you give appropriate credit to the original author(s) and the source, provide a link to the Creative Commons licence, and indicate if changes were made. The images or other third party material in this article are included in the article's Creative Commons licence, unless indicated otherwise in a credit line to the material. If material is not included in the article's Creative Commons licence and your intended use is not permitted by statutory regulation or exceeds the permitted use, you will need to obtain permission directly from the copyright holder. To view a copy of this licence, visit http://creativecommons.org/licenses/by/4.0/. The Creative Commons Public Domain Dedication waiver (http://creativecommons.org/publicdomain/zero/1.0/) applies to the data made available in this article, unless otherwise stated in a credit line to the data. 
metal circulation between Shu state and other states? The answers to these questions may fill the gap between southwest China and other areas of the country during the Warring States period.

However, few metallurgical studies on the Shu state bronzes have been conducted to date, which prevents further research on this topic [11]. Recently, a Shu state cemetery in Chengdu, known as Baishoulu, was excavated; in total, 28 bronze objects dating from the 5th to the third century BCE were recovered. The artefacts were scientifically analysed for the current research and compared with published data to gain a more thorough understanding of bronze production in the Shu state and its possible connections with states outside the Sichuan Basin.

\section{The Baishoulu cemetery}

The Baishoulu cemetery is located in the western section of Chengdu City (Fig. 1). Adjacent to the south side of the cemetery is the Modi river; the remaining three sides are bordered by roads. Overall, $2800 \mathrm{~m}^{2}$ were excavated over 2 years (from 2015 to 2016). Several tombs and other remains were revealed (see Fig. 2). These remains belong to three different periods, the 1st of which is the Warring States period (475-221 BCE). A total of 56 rectangular pit
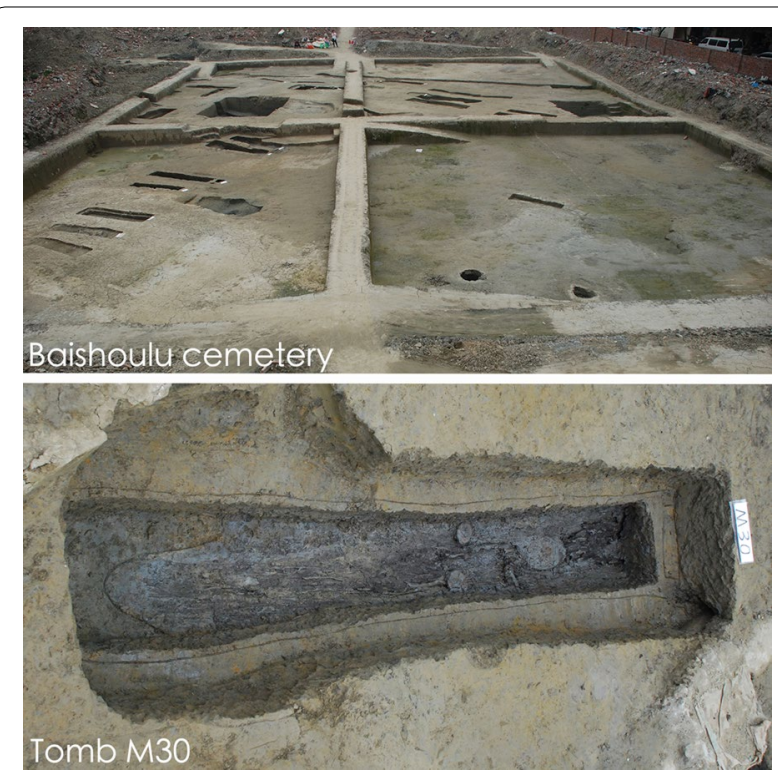

Fig. 2 Photographs of Baishoulu cemetery and a typical tomb inside the cemetery

tombs that were excavated dated to this time. The tombs contained long rectangular coffins, rather than canoeshaped coffins, and most belonged to people of a lower status compared with the Majia or Shangyejie tombs

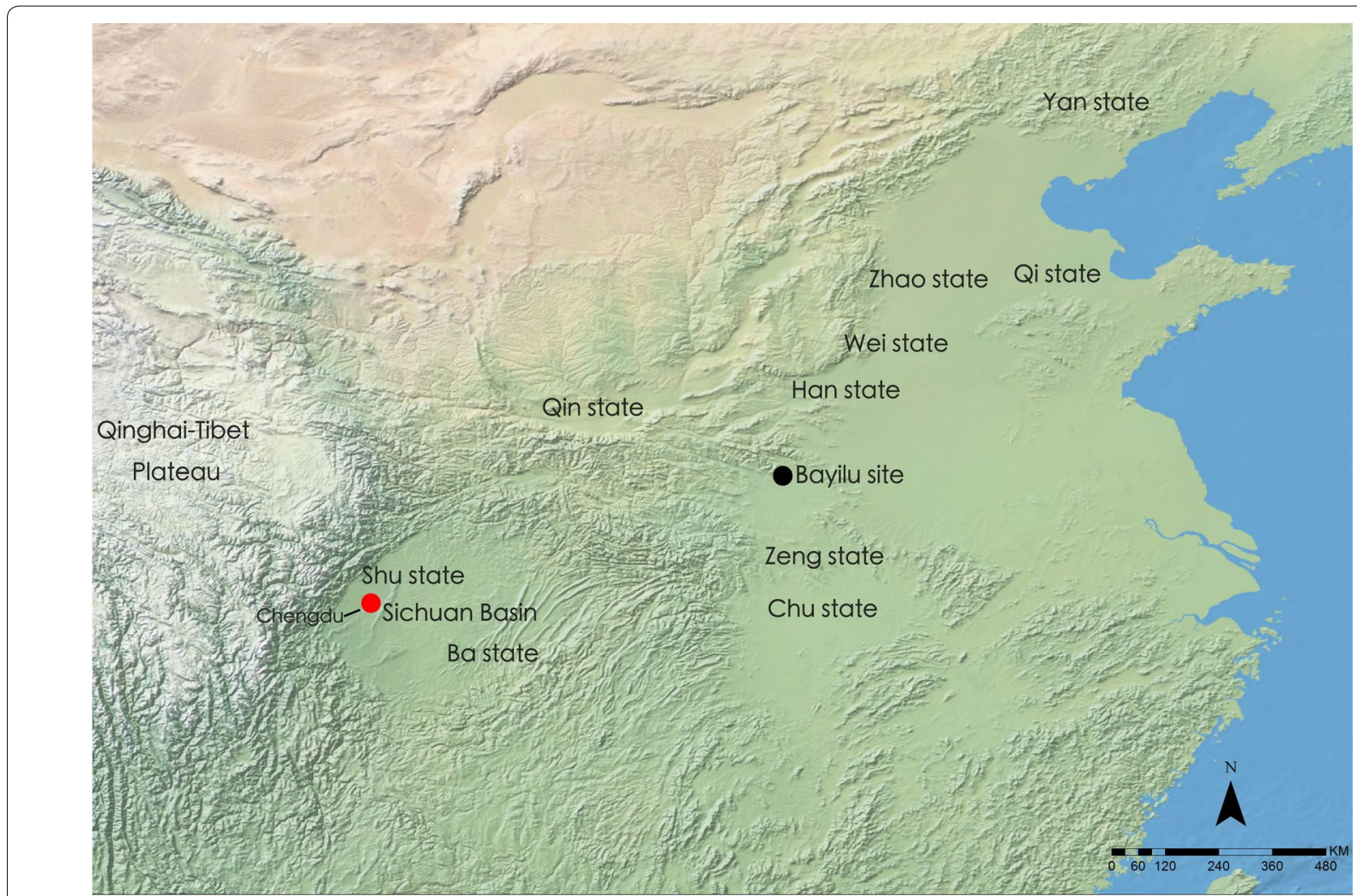

Fig. 1 Map of Sichuan Basin showing the sites and states mentioned in the text 
$[12,13]$. The definition of high- and low-status tombs was mainly based on the number of bronze objects and the tomb size. Many Shu state cemeteries and tombs in the Chengdu Plains have been excavated to date, and there are standards set for the varying statuses of tombs [14]. Most of the Baishoulu burial objects were pottery, including pots, jars, ring foot plates, and containers with pointed bottoms. The bronze objects unearthed included axes, swords, spears, dagger-axes, knives, a saw, stamps, and coins. Based on the typology study of the bronze objects and the date of the coins, most tombs were dated to the middle of the Warring States period (Fourth through third centuries BCE); several tombs may date to an earlier age based on the clear chronological features found on some artefacts.

The second period to which the tombs date is the Han Dynasty (202 BCE-220 CE). For this period, 2 urn burials, 1 rectangular pit tomb, 13 pits, 4 ditches, 2 pottery kilns, 1 house foundation, and 4 wells were excavated. Potteries such as jars, urns, basins, steamers, and bricks were found. The third period is between the late Tang Dynasty (755-907 CE) and the Five Dynasties (907-960 CE). A total of 26 brick structure tombs were revealed; the burial objects consisted mainly of porcelains, including jars and bowls.

\section{Materials and methods}

To understand the metallurgical characteristics of the bronzes from the Baishoulu cemetery, 28 samples were taken from the same number of individual objects. These artefacts were specifically chosen to ensure the inclusion of a variety of types and shapes of bronzes. The sampled objects, excavated from 16 lower-status noble tombs, included 7 knives in different shapes, 3 spears, 3 vessels, 4 swords, 2 dagger-axes, 2 bangles, 1 saw, 1 axe, 1 chariot bell, and 4 fragments from unknown vessels. One vessel and its grid were both sampled and studied as 2 individual objects (Fig. 3, BS21, 22). Detailed information on these samples is displayed in Table 1. Figure 3 depicts 19 complete or nearly complete artefacts; the remaining 9 were too small and will not be presented here. Invasive methods, including the use of a portable cutting machine (Dremel 4000) and pliers, were used to acquire samples. The authors removed a small chip (more than $100 \mathrm{mg}$ ) from each object; the sampling points are indicated in Fig. 3. All of the samples from tools and weapons were taken from the edge or blade of the object. Six samples were heavily or partly corroded, so the elemental results will not be included in this discussion.

Each sample was cut and split into two separate parts for mounting and dissolution. Most corroded samples were too small and not suitable for metallographic observation; the exception to this was BS22, whose

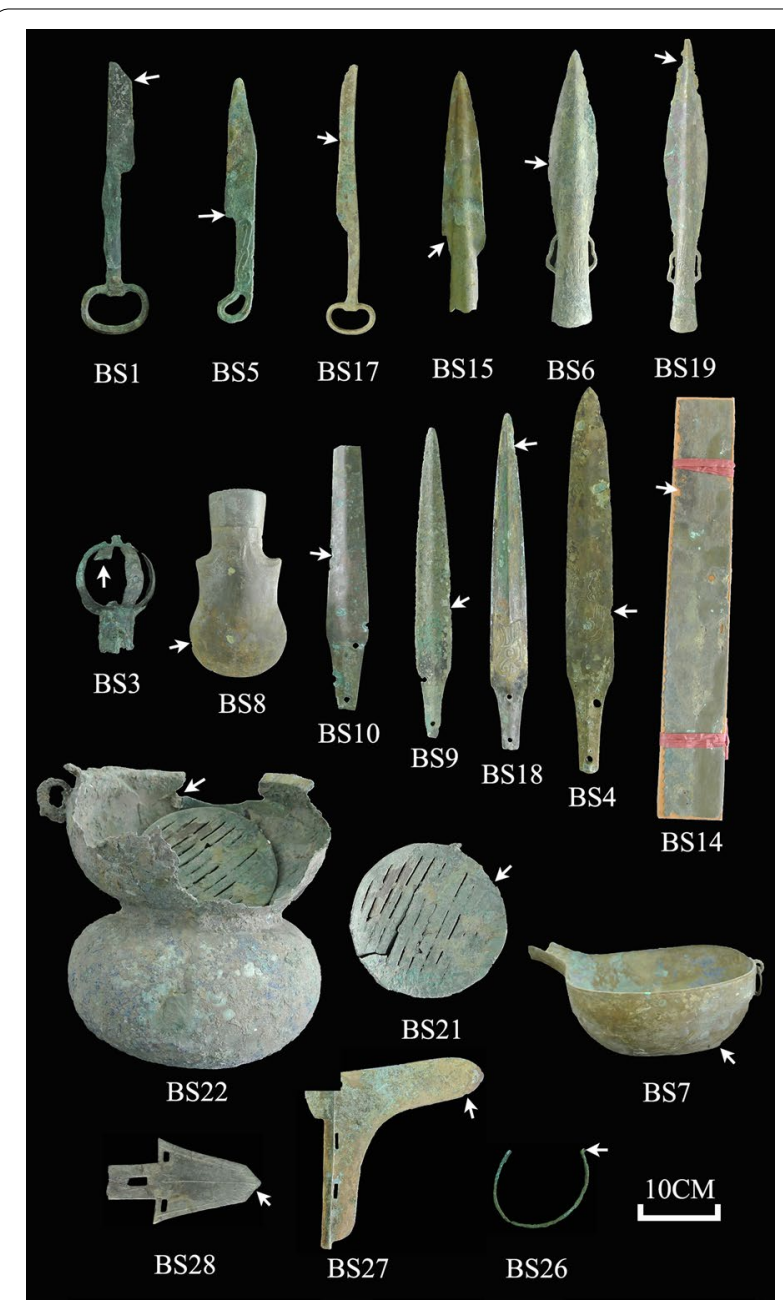

Fig. 3 Typical bronze objects from Baishoulu cemetery analysed in this research. The white arrows point to the sample points

portion of the sample was not corroded. The samples for mounting were cold mounted in epoxy resin. After solidification, Struers Tegramin-20 polish-grinding machine was employed to grind and polish the samples. Then, a Nikon LV-100 polarizing/metallographic microscope was used to observe the samples before and after etching with alcoholic ferric chloride solution $\left(\mathrm{FeCl}_{3}\right)(\mathrm{Scott} 1991)$.

The reference materials used for the calibration of the trace element analysis were produced by the NCS Testing Technology Co., Ltd. The single reference solution of $\mathrm{Sn}, \mathrm{Pb}, \mathrm{As}, \mathrm{Sb}, \mathrm{Ag}, \mathrm{Ni}, \mathrm{Fe}, \mathrm{Zn}, \mathrm{Se}, \mathrm{Te}, \mathrm{Au}$, and $\mathrm{Bi}$ was mixed for the secondary standard solution. The element concentration in each single reference material was $1000 \mathrm{ppm}$. The secondary standard solution was then separately diluted to $50,25,10,5,1$, and $0.5 \mathrm{ppm}$. These standards were used to build the 
Table 1 Context and types of the analysed bronze objects

\begin{tabular}{|c|c|c|c|c|}
\hline Object's number & Context number & Type & Sampling position & Corrosion \\
\hline BS1 & M1:4 & Knife & Edge & None \\
\hline BS2 & M1:5 & Vessel fragment & Edge & Heavily Corroded \\
\hline BS3 & M1:6 & Chariot bell & Middle part & None \\
\hline BS4 & M8:1 & Sword & Edge & None \\
\hline BS5 & M10:- & Knife & Edge & None \\
\hline BS6 & M10:22 & Spear & Edge & None \\
\hline BS7 & M12:1 & Vessel & Bottom & None \\
\hline BS8 & M14:1 & Axe & Edge & None \\
\hline BS9 & M19:- & Sword & Edge & None \\
\hline $\mathrm{BS} 10$ & M20:1 & Sword & Edge & None \\
\hline BS11 & $M 21: 3$ & Knife & Edge & None \\
\hline $\mathrm{BS} 12$ & M21:4 & Vessel fragment & Edge & None \\
\hline $\mathrm{BS} 13$ & M22:4 & Vessel fragment & Edge & None \\
\hline BS14 & M22:5 & Saw & Edge & None \\
\hline BS15 & M22:6 & Spear & Edge & Heavily Corroded \\
\hline BS16 & M24:1 & Vessel fragment & Edge & Heavily Corroded \\
\hline BS17 & M25:1 & Knife & Edge & None \\
\hline BS18 & $M 27: 1$ & Sword & Edge & None \\
\hline BS19 & $M 27: 2$ & Spear & Edge & Heavily Corroded \\
\hline BS20 & M30:1 & Knife & Edge & Heavily Corroded \\
\hline BS21 & M37:1-1 & Vessel's grid & Edge & None \\
\hline BS22 & M37:1-2 & Vessel & Near rim & Partly Corroded \\
\hline BS23 & M32:4 & Knife & Edge & None \\
\hline BS24 & M32:3 & Knife & Edge & None \\
\hline $\mathrm{BS} 25$ & M32:5-1 & Bangle & Broken part & None \\
\hline BS26 & M32:5-2 & Bangle & Broken part & None \\
\hline BS27 & M35:4 & Dagger-axe & Edge & None \\
\hline $\mathrm{BS} 28$ & M35:3 & Dagger-axe & Edge & None \\
\hline
\end{tabular}

The ' $M$ ' in the Context number represent 'Tomb', the number after ' $M$ ' is the Tomb number and the number after ':' is the object's number when excavated

calibration curve in the inductively coupled plasmaatomic emission spectrometer (ICP-AES). The samples for dissolution were cleaned to remove corrosion and contamination. After accurate weighing, they were then placed in aqua regia and heated with an electric heating plate (LabTech EG37B). After complete dissolution, the solutions were diluted with deionized water to $100 \mathrm{ml}$. The elemental compositions were measured using a Leeman Labs, Leeman Prodigy spectrometer (ICP-AES). The working conditions were as follows: RF power of $1.1 \mathrm{~kW}$, argon gas flow rate of $20 \mathrm{~L} / \mathrm{min}$, and nebulizer gas at $20 \mathrm{MPa}$. This experiment measured a total of 12 elements that might be useful for bronze studies, including $\mathrm{Sn}, \mathrm{Pb}, \mathrm{As}, \mathrm{Sb}, \mathrm{Ag}, \mathrm{Ni}, \mathrm{Fe}, \mathrm{Zn}, \mathrm{Se}, \mathrm{Te}$, $\mathrm{Au}$, and $\mathrm{Bi}$. A secondary reference solution including all 12 elements with known concentrations was used for quality control. For every 15 samples, the $5 \mathrm{ppm}$ secondary reference solution was measured to ensure the RSD (relative standard deviation) of each element was below $\pm 0.1 \%$. If the RSD were to rise above $\pm 0.1 \%$, the calibration curve would need to be rebuilt. The LOQ values of the ICP-AES remained in excellent condition. The RSD was below $0.1 \%$ within the measurement time of 150 samples.

Lead isotope ratios were measured using a VG Elemental multicollector-inductively coupled plasma mass spectrometer (MC-ICP-MS) (VG Elemental Axiom, Thermo Fisher Scientific Inc., USA). Based on the lead composition measured with ICP-AES, the solution was diluted to $1000 \mathrm{ppb}$ and added to the thallium (T1) standard SRM997. Then, the lead isotope was measured. The relative errors of the ${ }^{207} \mathrm{~Pb} /{ }^{206} \mathrm{~Pb}$, ${ }^{208} \mathrm{~Pb} /{ }^{206} \mathrm{~Pb}$, and ${ }^{206} \mathrm{~Pb} /{ }^{204} \mathrm{~Pb}$ ratios were $<0.01 \%, 0.01 \%$, and $0.1 \%$, respectively. The SRM981 international lead isotope standard was used as the standard reference to calibrate the spectrometer. The standard was remeasured for every set of 6-8 sample measurements. 


\section{Results and discussion}

\section{Metallographic analysis}

Based on the metallographic observations, the microstructures of the analysed samples can be classified into two types. The first type reveals a dendritic microstructure with a $(\alpha+\delta)$ eutectoid, $\mathrm{Cu}-\mathrm{S}$ inclusions, and lead inclusions, which suggests that they were cast without secondary processing [15, 16] (Fig. 4, BS3, BS10, BS22). The second type reveals worked and annealed grains with twinning (Fig. 4, BS14). This suggests that these artefacts were shaped by cold working and annealing $[15,16]$. The cold worked and annealed objects include both tools (knife and saw) and a weapon (spear). The cast objects include vessels (steamer and its grid), a weapon (sword), and an accessory (chariot bell).

During the Warring States period, casting was still the primary technique used to make vessels [10]. However, cold working and annealing techniques gained popularity for specific vessels decorated with hammered or carved motifs, as well as for other types of thin body vessels [17, 18]. These cold worked and annealed vessels existed in the Central Plains and Yangtze River basin states; however, there is no evidence to indicate their presence in the Shu state $[17,18]$.

There are questions on the techniques used for producing other types of objects, such as tools and weapons, in the Shu and surrounding states. The metallographic observation indicates that cold working and annealing techniques were both utilized in the production of tools and weapons; which provides the first evidence of such techniques being used on Shu state tools and weapons. However, a cast sword represents an alternative technique used on the weapons. The authors assume that the technique might be more complex as more samples are analysed in the future.

\section{Alloying techniques}

The results of the ICP-AES are revealed in Table 2, and the data are not normalized. While researchers have proposed different standards for defining alloy types, this research used the traditional $2 \%$ cut-off [19]. By this standard, 2 artefacts are $\mathrm{Cu}-\mathrm{Sn}$ alloys, 3 artefacts are $\mathrm{Cu}-\mathrm{Pb}$ alloys, and 17 artefacts are $\mathrm{Cu}-\mathrm{Sn}-\mathrm{Pb}$ alloys. All samples reveal variable tin and lead compositions.

The authors have aimed to disclose both the internal and external relationships associated with the Shu state bronzes with respect to alloying techniques. As such, the relationship between the features of the bronzes and the varying statuses of the tombs is discussed. In addition, the relationship of the Shu state bronzes with those from other states during the Warring States period is examined.

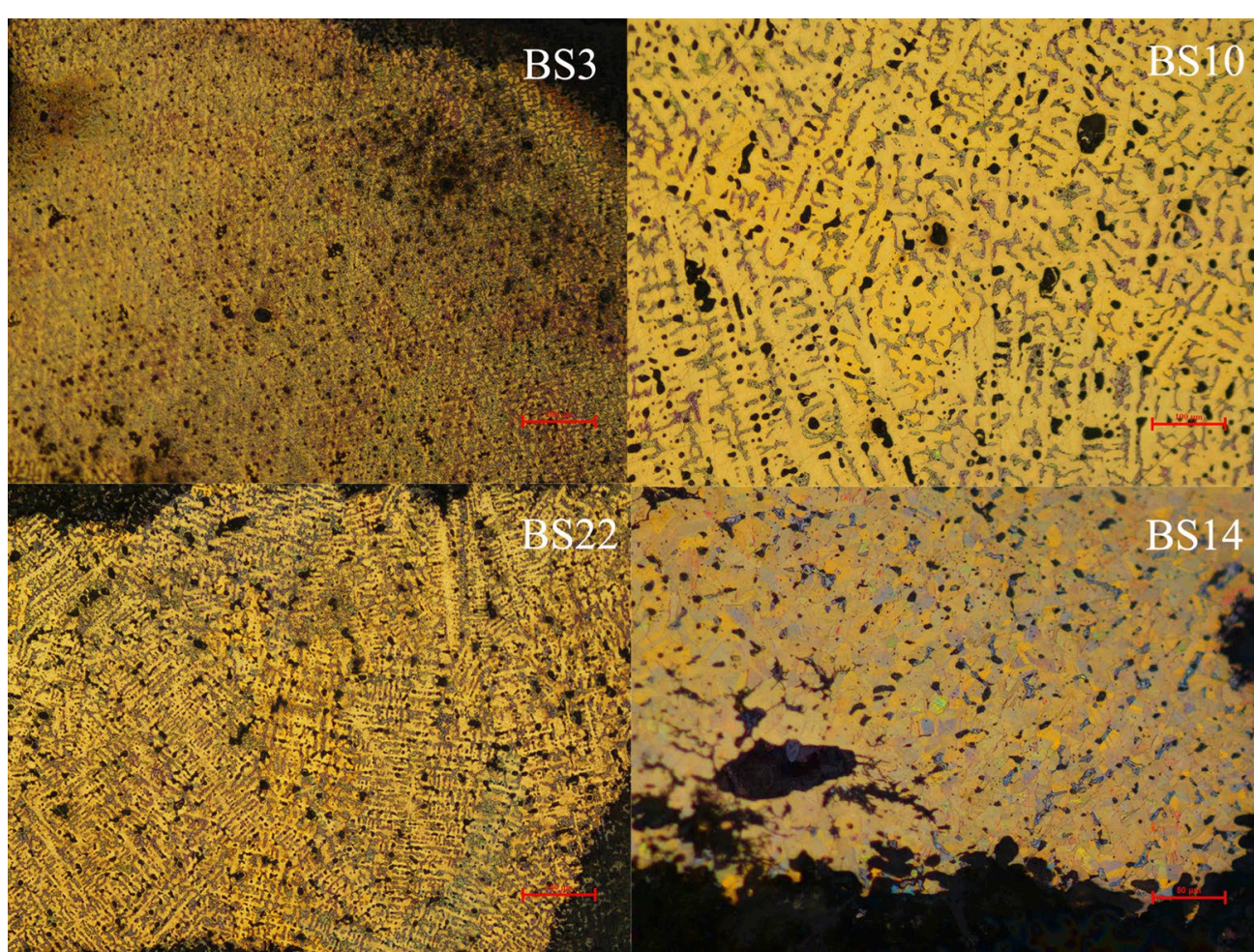

Fig. 4 Microstructures of the analysed samples 
Table 2 Results of ICP-AES analysis of samples from Baishoulu cemetery

\begin{tabular}{|c|c|c|c|c|c|c|c|c|c|c|c|c|c|c|c|}
\hline Object's number & Type & CG & Alloy types & Sn & $\mathrm{Pb}$ & As & $\mathrm{Sb}$ & $\mathrm{Ag}$ & $\mathrm{Ni}$ & $\mathrm{Fe}$ & $\mathrm{Zn}$ & $\mathrm{Se}$ & $\mathrm{Te}$ & $\mathrm{Au}$ & $\mathrm{Bi}$ \\
\hline BS1 & Knife & 4 & $\mathrm{Cu}-\mathrm{Sn}-\mathrm{Pb}$ & 18.2 & 3.6 & 164 & $<\mathrm{DL}$ & 1723 & 59 & 12,428 & $<\mathrm{DL}$ & 220 & 297 & $<\mathrm{DL}$ & 880 \\
\hline BS2 & Vessel fragment & 7 & Corroded & 25.3 & 0.2 & 220 & 1440 & 1008 & $<\mathrm{DL}$ & 3367 & $<\mathrm{DL}$ & $<\mathrm{DL}$ & 273 & $<\mathrm{DL}$ & 400 \\
\hline BS3 & Chariot bell & 7 & $\mathrm{Cu}-\mathrm{Sn}-\mathrm{Pb}$ & 17.1 & 6.8 & 81 & 2460 & 2212 & $<\mathrm{DL}$ & 371 & $<\mathrm{DL}$ & $<\mathrm{DL}$ & 284 & $<\mathrm{DL}$ & 370 \\
\hline BS4 & Sword & 4 & $\mathrm{Cu}-\mathrm{Sn}-\mathrm{Pb}$ & 13.8 & 2.3 & 117 & 680 & 2316 & 50 & 5091 & $<\mathrm{DL}$ & 83 & 231 & $<\mathrm{DL}$ & 550 \\
\hline BS5 & Knife & 1 & $\mathrm{Cu}-\mathrm{Sn}-\mathrm{Pb}$ & 19.2 & 5.4 & $<\mathrm{DL}$ & $<\mathrm{DL}$ & $<\mathrm{DL}$ & $<\mathrm{DL}$ & 13,504 & $<\mathrm{DL}$ & 474 & 297 & $<\mathrm{DL}$ & 472 \\
\hline BS6 & Spear & 4 & $\mathrm{Cu}-\mathrm{Sn}-\mathrm{Pb}$ & 11.6 & 15.4 & 113 & 142 & 2216 & $<\mathrm{DL}$ & 1461 & $<\mathrm{DL}$ & 255 & 144 & $<\mathrm{DL}$ & 479 \\
\hline BS7 & Vessel & 1 & $\mathrm{Cu}-\mathrm{Sn}-\mathrm{Pb}$ & 12.3 & 4.9 & 230 & $<\mathrm{DL}$ & 756 & 282 & 10,291 & $<\mathrm{DL}$ & 689 & 229 & $<\mathrm{DL}$ & 243 \\
\hline BS8 & Axe & 7 & $\mathrm{Cu}-\mathrm{Sn}-\mathrm{Pb}$ & 14.6 & 4.6 & 157 & 844 & 4073 & $<\mathrm{DL}$ & 756 & $<\mathrm{DL}$ & $<\mathrm{DL}$ & 97 & $<\mathrm{DL}$ & 551 \\
\hline BS9 & Sword & 7 & $\mathrm{Cu}-\mathrm{Sn}-\mathrm{Pb}$ & 4.0 & 23.5 & 222 & 2691 & 3591 & 91 & 18,384 & 177 & 240 & 371 & 171 & 336 \\
\hline $\mathrm{BS} 10$ & Sword & 7 & $\mathrm{Cu}-\mathrm{Sn}-\mathrm{Pb}$ & 13.0 & 6.6 & 165 & 1542 & 3260 & 57 & 2452 & $<\mathrm{DL}$ & 89 & 209 & $<\mathrm{DL}$ & 397 \\
\hline BS11 & Knife & 4 & $\mathrm{Cu}-\mathrm{Pb}$ & 1.0 & 3.1 & $<\mathrm{DL}$ & $<\mathrm{DL}$ & 4696 & $<\mathrm{DL}$ & 6209 & $<\mathrm{DL}$ & $<\mathrm{DL}$ & 486 & $<\mathrm{DL}$ & 534 \\
\hline $\mathrm{BS} 12$ & Vessel fragment & 7 & $\mathrm{Cu}-\mathrm{Sn}-\mathrm{Pb}$ & 12.8 & 17.3 & 68 & 983 & 2273 & 75 & 11,877 & $<\mathrm{DL}$ & $<\mathrm{DL}$ & 405 & $<\mathrm{DL}$ & 415 \\
\hline $\mathrm{BS} 13$ & Vessel fragment & 4 & $\mathrm{Cu}-\mathrm{Sn}-\mathrm{Pb}$ & 10.0 & 6.2 & 87 & 813 & 1719 & $<\mathrm{DL}$ & 1855 & $<\mathrm{DL}$ & 245 & 221 & $<\mathrm{DL}$ & 327 \\
\hline $\mathrm{BS} 14$ & Saw & 7 & $\mathrm{Cu}-\mathrm{Sn}-\mathrm{Pb}$ & 13.6 & 3.3 & 109 & 1233 & 2771 & $<\mathrm{DL}$ & 2836 & $<\mathrm{DL}$ & $<\mathrm{DL}$ & 275 & $<\mathrm{DL}$ & 446 \\
\hline BS15 & Spear & 7 & Corroded & 22.1 & 2.6 & 251 & 2338 & 1854 & $<\mathrm{DL}$ & 10,456 & $<\mathrm{DL}$ & 198 & 392 & $<\mathrm{DL}$ & 579 \\
\hline $\mathrm{BS} 16$ & Vessel fragment & 7 & Corroded & 24.1 & 2.7 & 363 & 1823 & 2094 & 70 & 10,781 & $<\mathrm{DL}$ & 463 & 57 & $<\mathrm{DL}$ & 756 \\
\hline $\mathrm{BS} 17$ & Knife & 4 & $\mathrm{Cu}-\mathrm{Sn}-\mathrm{Pb}$ & 10.1 & 5.9 & 61 & 609 & 2726 & $<\mathrm{DL}$ & 979 & $<\mathrm{DL}$ & $<\mathrm{DL}$ & 311 & $<\mathrm{DL}$ & 456 \\
\hline $\mathrm{BS} 18$ & Sword & 7 & $\mathrm{Cu}-\mathrm{Sn}-\mathrm{Pb}$ & 14.9 & 6.1 & 444 & 1090 & 1521 & 78 & 4351 & $<\mathrm{DL}$ & 1960 & 510 & $<\mathrm{DL}$ & 602 \\
\hline $\mathrm{BS} 19$ & Spear & 7 & Corroded & 23.2 & 4.2 & 329 & 2654 & 2999 & 78 & 15,016 & $<\mathrm{DL}$ & 671 & 447 & $<\mathrm{DL}$ & 410 \\
\hline $\mathrm{BS} 20$ & Knife & 7 & Corroded & 24.5 & 4.8 & 151 & 844 & 4691 & $<\mathrm{DL}$ & 15,178 & $<\mathrm{DL}$ & $<\mathrm{DL}$ & 233 & $<\mathrm{DL}$ & 682 \\
\hline BS21 & Vessel's grid & 4 & $\mathrm{Cu}-\mathrm{Pb}$ & 1.0 & 8.6 & $<\mathrm{DL}$ & $<\mathrm{DL}$ & 1442 & $<\mathrm{DL}$ & 977 & $<\mathrm{DL}$ & $<\mathrm{DL}$ & 318 & $<\mathrm{DL}$ & 276 \\
\hline $\mathrm{BS} 22$ & Vessel & 7 & Corroded & 26.0 & 17.1 & 172 & 3818 & 5572 & 232 & 11,302 & $<\mathrm{DL}$ & $<\mathrm{DL}$ & 217 & 58 & 610 \\
\hline $\mathrm{BS} 23$ & Knife & 4 & $\mathrm{Cu}-\mathrm{Pb}$ & 0.5 & 4.1 & $<\mathrm{DL}$ & $<\mathrm{DL}$ & 3296 & $<\mathrm{DL}$ & 3721 & $<\mathrm{DL}$ & 220 & 357 & $<\mathrm{DL}$ & 292 \\
\hline BS24 & Knife & 4 & $\mathrm{Cu}-\mathrm{Sn}-\mathrm{Pb}$ & 4.6 & 16.9 & $<\mathrm{DL}$ & $<\mathrm{DL}$ & 6217 & 73 & 2205 & $<\mathrm{DL}$ & $<\mathrm{DL}$ & 324 & 68 & 487 \\
\hline BS25 & Bangle & 1 & $\mathrm{Cu}-\mathrm{Sn}$ & 5.3 & 0.2 & 191 & 817 & 364 & $<\mathrm{DL}$ & 6200 & $<\mathrm{DL}$ & $<\mathrm{DL}$ & 382 & $<\mathrm{DL}$ & 337 \\
\hline $\mathrm{BS} 26$ & Bangle & 3 & $\mathrm{Cu}-\mathrm{Sn}$ & 8.9 & 0.5 & 309 & 1592 & 744 & $<\mathrm{DL}$ & 5251 & $<\mathrm{DL}$ & $<\mathrm{DL}$ & 657 & $<\mathrm{DL}$ & 568 \\
\hline $\mathrm{BS} 27$ & Dagger-axe & 7 & $\mathrm{Cu}-\mathrm{Sn}-\mathrm{Pb}$ & 12.1 & 5.4 & 249 & 13,316 & 3526 & 53 & 1780 & $<\mathrm{DL}$ & $<\mathrm{DL}$ & 245 & $<\mathrm{DL}$ & 456 \\
\hline $\mathrm{BS} 28$ & Dagger-axe & 7 & $\mathrm{Cu}-\mathrm{Sn}-\mathrm{Pb}$ & 17.7 & 8.2 & 133 & 2088 & 2345 & 87 & 4509 & $<\mathrm{DL}$ & 452 & 120 & $<\mathrm{DL}$ & 478 \\
\hline
\end{tabular}

Sn and Pb (wt\%), other elements $(\mu \mathrm{g} / \mathrm{g}),{ }^{\prime} \mathrm{CG}$ ' represent 'Copper Groups,', $<\mathrm{DL}$ ' represent 'Below detection limit'

Figure 5 presents the scatter plot of $\mathrm{Pb}$ versus $\mathrm{Sn}$ in bronze objects from different sites in Chengdu; this demonstrates whether the alloying technique was the same. Three sites were involved in the comparison: Majia, Luojianian, and Zaozixiang. All three sites are tombs from the Warring States period that contained bronze objects. The Majia tomb, one of the largest tombs discovered in Chengdu, represents a high-status tomb [13]. The other tombs, from Luojianian and Zaozixiang, are smaller in comparison, and both are low-status tombs similar to those found in the Baishoulu cemetery.

Zeng analysed 43 bronze objects from the Majia tomb, including spears, dagger-axes, swords, axes, knives, arrowheads, chisels, and vessels [11]. He also analysed 4 bronze objects from the Luojianian tomb and 7 bronze objects from the Zaozixiang tomb, all of which were

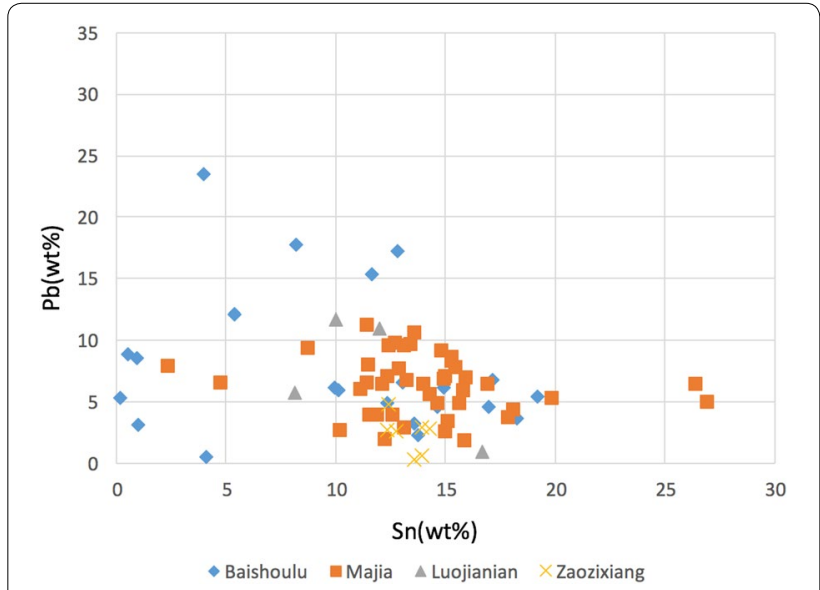

Fig. 5 Scatter plot indicating the Pb versus $\mathrm{Sn}$ of the bronze objects from Baishoulu cemetery and other sites in Chengdu 
weapons. Most bronze objects were analysed using the spectrophotometry method, except for 3 objects from Luojianian, which were analysed using scanning electron microscopy coupled with energy-dispersive spectroscopy (SEM-EDS) and atomic absorption spectrometry (AAS). There are often issues when comparing data from various techniques due to the different accuracy and detection limits, as well as the variances in the advantages and disadvantages of each technique. However, we believe that a comparison of major elements is worth exploring considering the lack of data published in this region. The comparison shows that most data were scattered in the same area (Sn:10-20\%; Pb:0-11\%) (Fig. 5). No clear difference can be seen between the high- and low-status tombs. On the other hand, compared with other locations, the Zaozixiang data is more clustered while the Baishoulu samples are more scattered. Considering that the Zaozixiang data came from a single tomb while the Baishoulu data came from more than ten different tombs, the different distribution might suggest that some of the bronze from the Zaozixiang low-status tomb might share a common production background.

Figure 6 presents a comparison between the Baishoulu samples and samples from three additional states in the Warring States period. Different types of artefacts were also compared. The Chu state objects and Jin-Han objects were both measured with ICP-AES [20, 21]; the Qi state objects were measured with SEM-EDS [22]. The accessories, weapons, tools, and vessels reveal many overlaps.

The earliest description of the various alloying compositions used in different types of objects in China was recorded in the historical literature, The Ritual Works of Zhou.Artificers Record (zhouli.kaoguji) [23]. Scholars hold varied opinions because the record does not correspond with the current bronze analysis [24-26]. There is a question as to whether the Shu state corresponds with this historical literature. As shown in Fig. 6, there is no clear pattern between the alloy composition of the tools, weapons, vessels, and accessories from Baishoulu cemetery. Therefore, the Baishoulu data does not provide any support for the record, even though the literature was thought to have been written in the early Warring States period [27]. Moreover, the comparison between the Shu state and other states in Fig. 6 leads to no clear pattern except that some of the bronzes from other states contain more than $20 \%$ tin.

\section{Trace elements analysis}

In this paper, trace elements and lead isotope ratios were used to study the possible ore sources. Trace elements
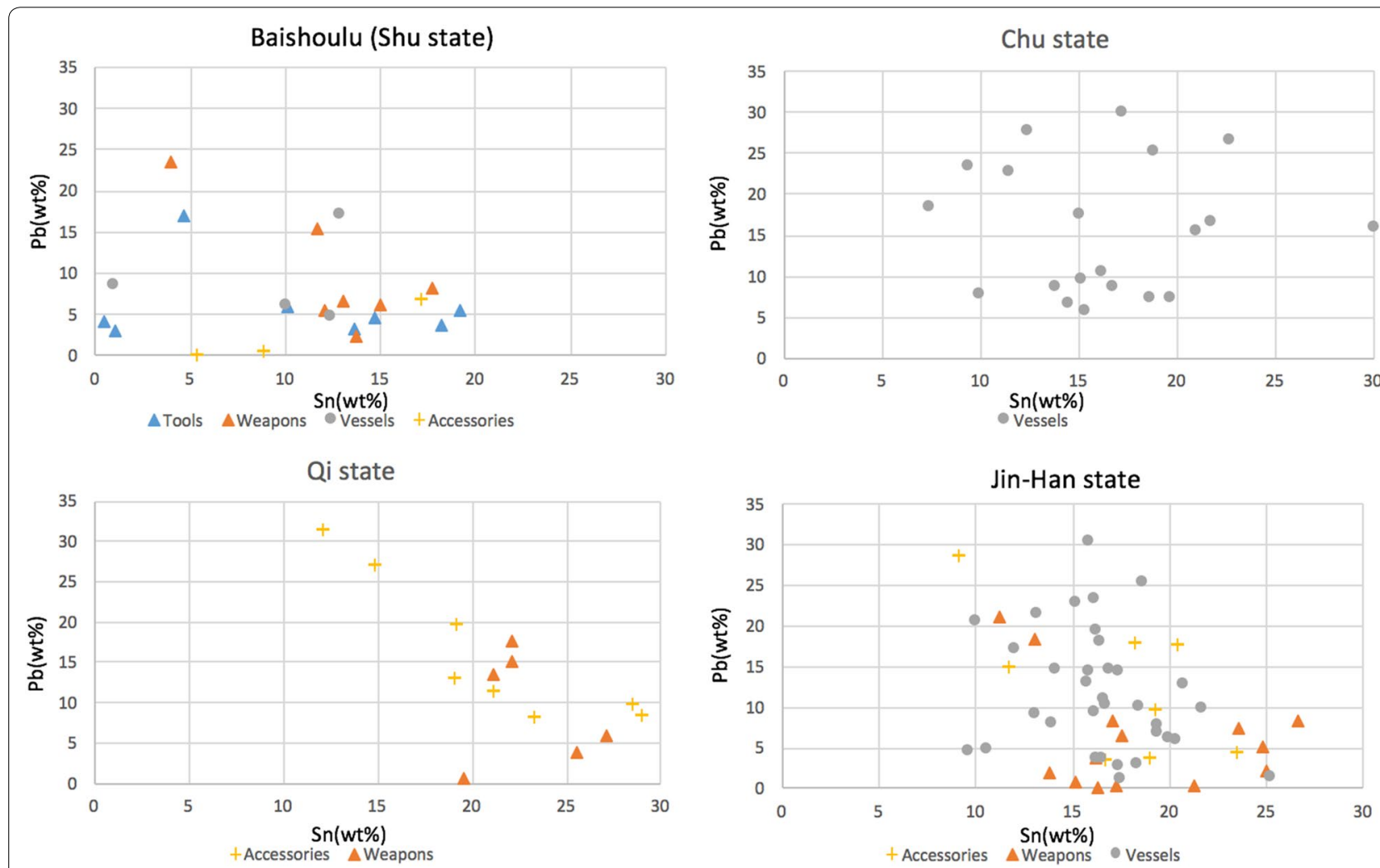

Fig. 6 Scatter plot revealing the Pb versus $\mathrm{Sn}$ of different types of bronzes from different states 
provide useful information when studying metal sources. The $1 \%$ cut-off was used to define trace elements in this paper. According to the ICP-AES results shown in Table 2, most elements were measured below 1\%, except for tin and lead. Moreover, 1 sample (BS27) contained more than $1 \%$ antimony, and 10 samples contained more than $1 \%$ iron. Using $0.1 \%$ as a threshold, antimony, silver, and iron revealed relatively higher compositions than other trace elements. Among the total 28 samples, 14 samples contained more than $0.1 \%$ antimony, and 24 samples contained more than $0.1 \%$ silver.

Arsenic, antimony, silver, and nickel are considered more suitable for classifying materials [28]. A method for classifying the data is necessary to compare the trace elements pattern. In this study, the authors applied the 'Copper Groups' method proposed by the research team led by Professor Mark Pollard in the Research Laboratory for Archaeology and the History of Art at the University of Oxford. This method belongs to the Oxford System. This system also includes the analysis of alloys and lead isotope data to pursue the circulation of copper and copper alloys [29-31]. Based on the presence or absence of arsenic, antimony, silver, and nickel, and using $0.1 \%$ as a cut-off, 16 'Copper Groups' were defined to provide a classification standard. These four elements were chosen because most published trace elemental data includes them. Moreover, these elements cover a range of thermodynamic behaviours in molten copper [31]. The possible combinations of presence and absence for the 4 elements provide 16 groups. With an additional element included, it would become 32 groups, which would be too cumbersome. This method shows its strength in universality and especially shows advantages in large scale comparisons. The current case studies show that the four elements grouping is usually enough to characterize changes in the material record [31].

Some possible problems need to be clarified. First, the relation between copper groups and ore sources is complicated. A single ore source might show multiple copper groups and a single copper group might come from multiple mines. Nevertheless, the method focuses on interregional, chronological, or typological patterns rather than on mines [31]. Another problem is that some of the four elements do not necessarily come from copper. For instance, silver in the alloy might be associated with the lead. However, the copper groups method aims only to detect changes in the composition in the metal flow, and the silver is a metal-flow marker [31]. Therefore, with sufficient archaeological context, this method should enable the comparison of trace elemental patterns with past and future data in a clearer manner.

Table 2 reveals the results of the 'Copper Groups' analysis. There are four groups present: CG1 (clean metal),
CG3 (Sb), CG4 (Ag), and CG7 (Ag+Sb). Apparently, silver and antimony are the two elements that require attention. The calculation indicates that CG4 and CG7 compose $82 \%$ of all samples (Table 2). CG 1 and CG 3 account for 14 and $4 \%$, respectively.

Although the analysis should include 'Copper Groups' from other states of the Warring States period, trace elemental data is unavailable for most states. The only reference data available include trace elemental data from the 20 bronzes of the Bayilu site, which belong to the Chu state [20]. 'Copper Groups' analysis indicates that $40 \%$ of the samples are CG7, and 50\% are CG12 (As + Ag + Sb); $\mathrm{CG} 13(\mathrm{Ag}+\mathrm{Sb}+\mathrm{Ni})$ and CG16 (As $+\mathrm{Ag}+\mathrm{Sb}+\mathrm{Ni})$ respectively account for $5 \%$. The connection between the Bayilu samples and the Baishoulu samples is the primary CG7, as all other copper groups are different.

Considering that the ratios of arsenic and antimony compositions are usually relative to the ore types. The ratios of silver and nickel remained quite stable in smelting and metal treatment, indicating the ore used [32, 33]. This study included an analysis of the four elements directly in the diagrams. Figure 7 reveals the diagrams of arsenic vs antimony and silver vs nickel. The Baishoulu bronzes and Bayilu bronzes were clearly clustered in different areas, with only a small number of overlap. Both the copper groups result and the comparison of ratios between four elements show major difference between these two states. Since no evidence shows any difference of the smelting, refining and alloying technique between the Shu and Chu state bronzes, the difference possibly indicates different metal materials. Considering that the lead sources used by these two states are almost the same, which will be elaborated upon in the following section, the varying trace elemental patterns might indicate that the copper, tin, or mixed materials are different.

In addition to the above, the analyses also included plotting the lead concentration against the silver concentration, as these two elements are often related. Both Baishoulu and Bayilu data were included in Fig. 8, but the plot shows no clear positive correlation between the lead and silver. Therefore, no evidence supports the idea that the silver was introduced through a lead source in the Baishoulu and Bayilu data.

\section{Lead isotope analysis}

The results of the lead isotope analyses are presented in Table 3 and Figs. 9, 10, 11, 12 and 13. For data with lead content between $50 \mathrm{ppm}$ and $4 \%$, the lead is usually considered to have been introduced by copper ores rather than through deliberate addition [34-36]. In this study, 9 samples ( 3 corroded) contained less than $4 \%$ lead, and the remaining 19 samples ( 3 corroded) contained more than $4 \%$ lead. A comparison between the samples with 


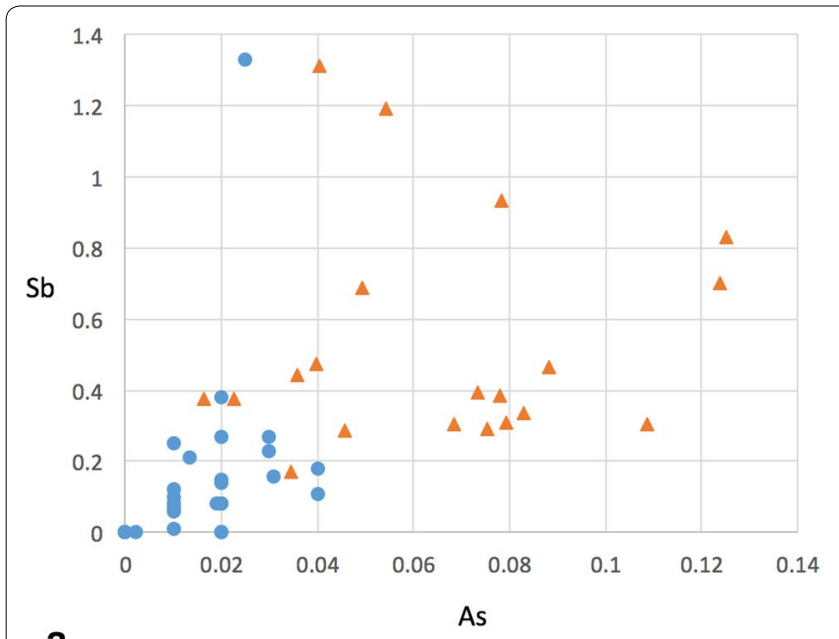

a

- Shu-Baishoulu $\triangle$ Chu-Bayilu

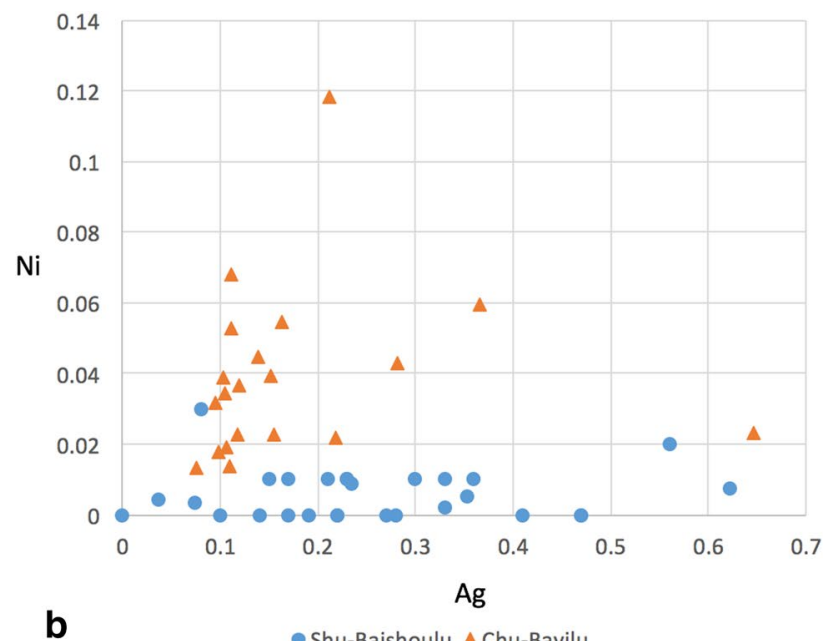

- Shu-Baishoulu $\triangle$ Chu-Bayilu

Fig. 7 Diagram for the trace elements As versus Sb (a; on the left) and Ag versus Ni (b; on the right); all data were given in mass percent

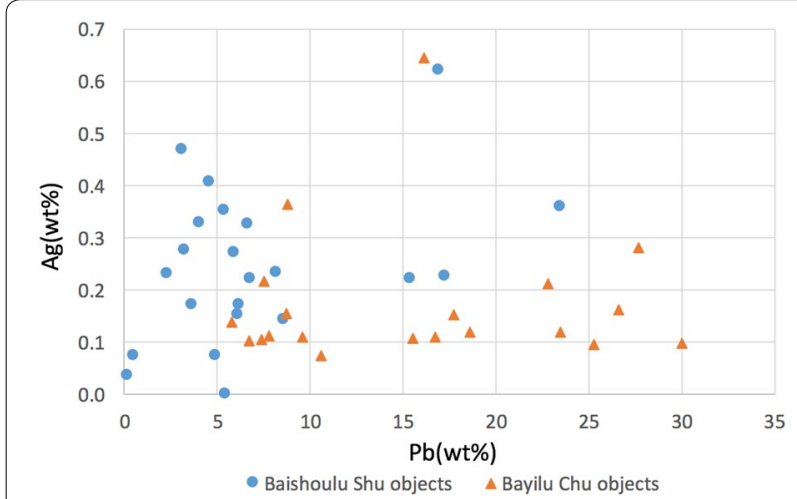

Fig. 8 Diagram for the elements $\mathrm{Pb}$ versus Ag; all data were given in mass percent

$\mathrm{Pb}<4 \%$ and $\mathrm{Pb} \geq 4 \%$ indicates that most data overlap with each other, and the samples with $\mathrm{Pb} \geq 4 \%$ covered a larger area (Fig. 9). Therefore, the lead isotope data in this paper were applied to discuss lead sources rather than copper. An additional cut-off of $2 \%$ was also proposed to distinguish intentionally added lead from natural impurities [37]. A comparison of the data based on the $2 \%$ cutoff and the extreme similarities in the results indicates numerous overlaps.

Figures 9 and 10 reveal that the Baishoulu data were distributed between 17.356 and 18.573 on ${ }^{206} \mathrm{~Pb} /{ }^{204} \mathrm{~Pb}$, 15.466 and 15.698 on ${ }^{207} \mathrm{~Pb} /{ }^{204} \mathrm{~Pb}$, and 38.008 and 39.123 on ${ }^{208} \mathrm{~Pb} /{ }^{204} \mathrm{~Pb}$. The authors assume that this area might include multiple lead sources. Thus far, no lead isotope data pertaining to the Shu state bronze objects have been published. However, the bronzes from other states of the same period could be used as a reference for the comparison. There are seven states that were considered to be the most powerful in the Warring States period, including the Qi, Chu, Yan, Han, Zhao, Wei, and Qin states (Fig. 1) [1, 2]. Ultimately, the Qin state conquered all others and built the Qin Dynasty. Located in the isolated Sichuan Basin, the relationship between the Shu state and the other states was rarely recorded in historical literature. Thus far, lead isotope data for bronzes of several states have been published, including the Chu and Zeng states [20-22, 38, 39].

Jin studied coins from 4 different states, including the Yan, Qi, Wei, and Chu states, which provides proper reference data [40]. Coins from each state have a unique style, and the name of the state is occasionally inscribed on the coin. Therefore, the coins are rather morphologically distinguishable and provide a baseline for comparison. Figures 12 and 13 depict the comparison of lead isotopes between bronzes of the Baishoulu cemetery and coins and other objects from other states. The most important phenomenon observed in this comparison is that most of the Baishoulu data overlap with the Zeng state objects. Moreover, the Chu coins, Bayilu Chu objects, and other locations' Chu objects reveal many overlaps, and most of them were distributed in the same area as the Zeng state objects. Since most of the samples from the Zeng state and the Chu state also contain more than $4 \%$ lead, the large area covered by Shu, Zeng, and Chu state bronzes probably indicates multiple lead sources. It is reasonable to conclude that the lead sources used by the Zeng and Chu states are similar.

In addition, the Zeng and Chu states have intimate geographical, cultural, and political relations [41]; thus, 
Table 3 Lead isotopic ratios measured on the bronze objects from Baishoulu cemetery

\begin{tabular}{|c|c|c|c|c|c|c|}
\hline Object's number & Type & ${ }^{208} \mathrm{~Pb} /{ }^{204} \mathrm{~Pb}$ & ${ }^{207} \mathrm{~Pb} /{ }^{204} \mathrm{~Pb}$ & ${ }^{206} \mathrm{~Pb} /{ }^{204} \mathrm{~Pb}$ & ${ }^{207} \mathrm{~Pb} /{ }^{206} \mathrm{~Pb}$ & ${ }^{208} \mathrm{~Pb} /{ }^{206} \mathrm{~Pb}$ \\
\hline BS1 & Knife & 38.462 & 15.602 & 17.934 & 0.8699 & 2.1446 \\
\hline BS2 & Vessel fragment & 38.593 & 15.605 & 18.255 & 0.8548 & 2.1141 \\
\hline $\mathrm{BS} 3$ & Chariot bell & 38.461 & 15.583 & 17.881 & 0.8715 & 2.1510 \\
\hline BS4 & Sword & 38.701 & 15.658 & 18.247 & 0.8581 & 2.1209 \\
\hline BS5 & Knife & 38.860 & 15.696 & 18.552 & 0.8460 & 2.0947 \\
\hline BS6 & Spear & 38.130 & 15.490 & 17.428 & 0.8888 & 2.1879 \\
\hline BS7 & Vessel & 38.008 & 15.470 & 17.356 & 0.8913 & 2.1901 \\
\hline BS8 & Axe & 38.178 & 15.466 & 17.659 & 0.8758 & 2.1619 \\
\hline BS9 & Sword & 38.099 & 15.575 & 17.716 & 0.8792 & 2.1505 \\
\hline $\mathrm{BS} 10$ & Sword & 38.347 & 15.556 & 17.863 & 0.8708 & 2.1468 \\
\hline BS11 & Knife & 38.440 & 15.576 & 17.871 & 0.8716 & 2.1509 \\
\hline $\mathrm{BS} 12$ & Vessel fragment & 39.123 & 15.548 & 18.137 & 0.8573 & 2.1569 \\
\hline BS13 & Vessel fragment & 38.385 & 15.580 & 17.897 & 0.8706 & 2.1448 \\
\hline BS14 & Saw & 38.497 & 15.603 & 17.965 & 0.8686 & 2.1430 \\
\hline BS15 & Spear & 38.612 & 15.621 & 18.171 & 0.8598 & 2.1253 \\
\hline $\mathrm{BS} 16$ & Vessel fragment & 38.623 & 15.629 & 18.106 & 0.8632 & 2.1331 \\
\hline $\mathrm{BS} 17$ & Knife & 38.552 & 15.568 & 17.904 & 0.8695 & 2.1533 \\
\hline $\mathrm{BS} 18$ & Sword & 38.725 & 15.657 & 18.214 & 0.8597 & 2.1262 \\
\hline BS19 & Spear & 38.608 & 15.637 & 18.250 & 0.8568 & 2.1155 \\
\hline $\mathrm{BS} 20$ & Knife & 38.711 & 15.651 & 18.286 & 0.8559 & 2.1170 \\
\hline BS21 & Vessel's grid & 38.762 & 15.660 & 18.359 & 0.8530 & 2.1114 \\
\hline $\mathrm{BS} 22$ & Vessel & 38.796 & 15.671 & 18.364 & 0.8534 & 2.1127 \\
\hline $\mathrm{BS} 23$ & Knife & 38.569 & 15.628 & 18.180 & 0.8596 & 2.1214 \\
\hline BS24 & Knife & 38.605 & 15.605 & 18.183 & 0.8582 & 2.1241 \\
\hline $\mathrm{BS} 25$ & Bangle & 38.734 & 15.630 & 18.499 & 0.8449 & 2.0939 \\
\hline $\mathrm{BS} 26$ & Bangle & 38.915 & 15.698 & 18.573 & 0.8452 & 2.0953 \\
\hline $\mathrm{BS} 27$ & Dagger-axe & 38.174 & 15.504 & 17.518 & 0.8850 & 2.1792 \\
\hline $\mathrm{BS} 28$ & Dagger-axe & 38.581 & 15.622 & 18.068 & 0.8646 & 2.1354 \\
\hline
\end{tabular}
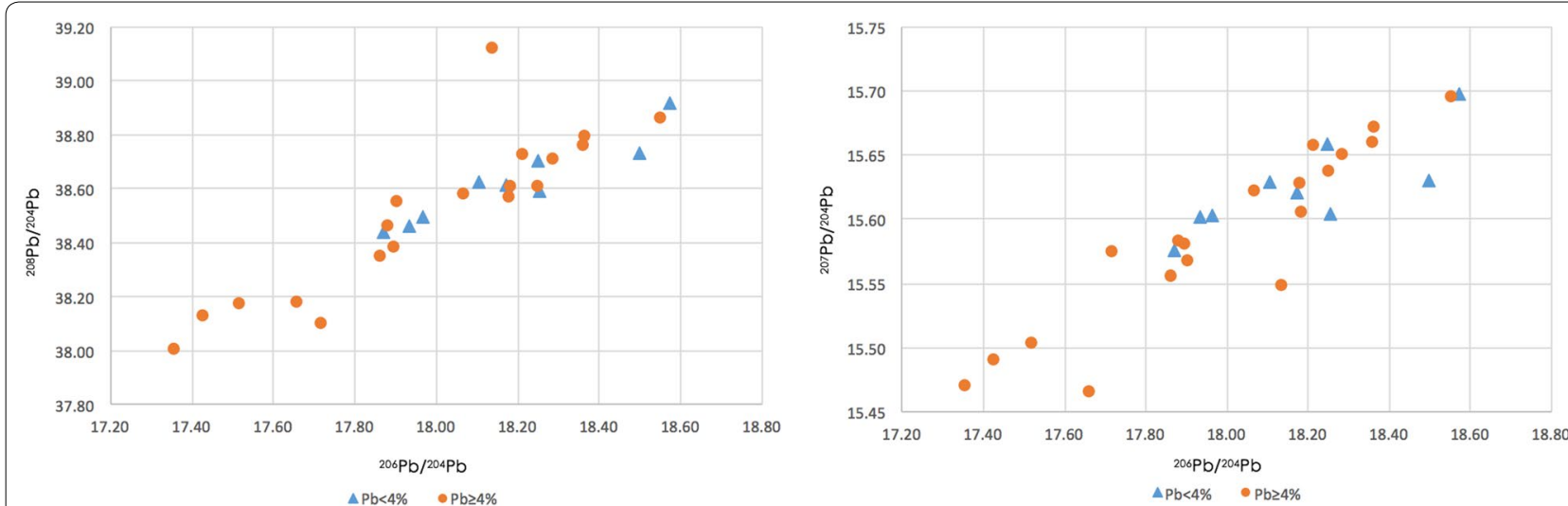

Fig. 9 Comparison of the lead isotope ratios between samples with $\mathrm{Pb}<4 \%$ and samples with $\mathrm{Pb} \geq 4 \%$

it is difficult to distinguish the material culture between these 2 states. The Zeng state was a small, dependent state of the powerful Chu state, and was quite wealthy.
The famous tomb of Yi, the Zeng duke, from the early Warring States period contained more than ten tonnes of bronze objects in addition to fine gold, jade artefacts, and 


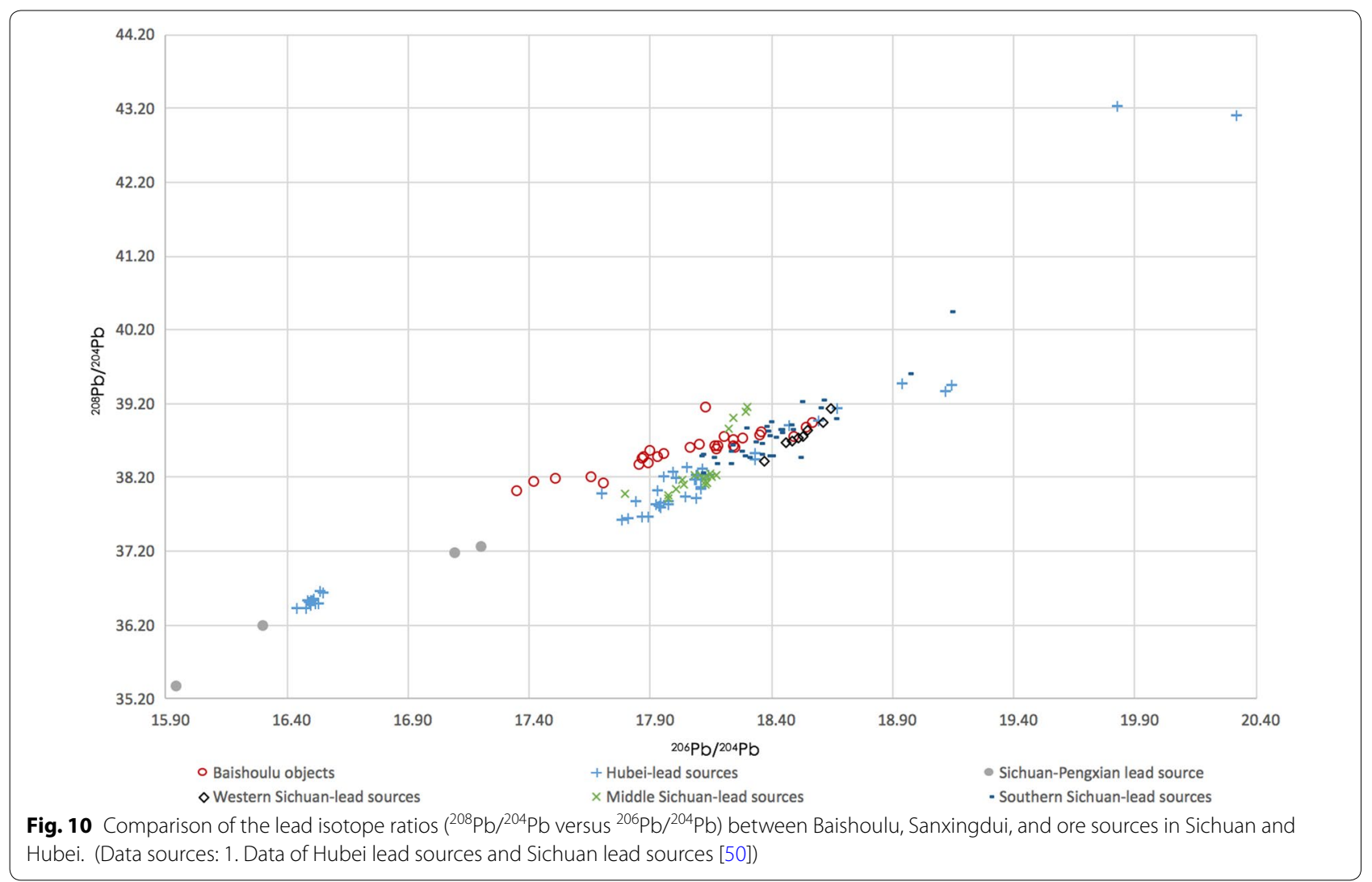

lacquers [42]. Both the Zeng and Chu states were located around the middle Yangtze River, which is home to the most abundant copper sources in China. Archaeological evidence reveals that the Chu state controlled the copper mining in the middle and lower Yangtze River during the Warring States period [43]. Thus, the Chu and Zeng states may have shared these abundant copper sources at that time. However, there are few clues regarding the lead sources for these 2 states. The common lead sources used by the Chu, Zeng, and Shu states suggest that a lead exchange route may have existed between them. Based on archaeological evidence, many Chu style bronze, pottery, and tombs were found in the Shu state; this discloses the close relationship maintained between the Chu and Shu states [44, 45]. These 2 states were connected by the Yangtze River, which could have been a part of the potential lead circulation route.

On the other hand, other possibilities also existed besides the relationship between Zeng state and Chu state. Zhang and Chen conducted a systematic lead isotopic study on the Eastern Zhou period bronzes in China [46]. They argued that 4 types of ore sources were used, namely A type $\left({ }^{208} \mathrm{~Pb} /{ }^{206} \mathrm{~Pb}=2.12-2.14\right)$,

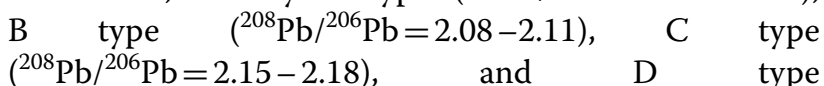

$\left({ }^{208} \mathrm{~Pb} /{ }^{206} \mathrm{~Pb}=>2.20\right)$. In this case, the lower end of Baishoulu bronzes corresponds well with the $C$ type, which also matched well with the Wei coins. They believe that the $\mathrm{C}$ type source was widely used in the Central Plains and surrounding regions from the late Spring and Autumn period to the early Warring States period. The geological origin of $C$ type ore sources was possibly located in western Henan and surrounding regions [37, 47]. Therefore, the Baishoulu artefacts matched with the $C$ type reveal that the lead sources' circulation might be much more complex and not constricted in the relationship with the Zeng state and Chu state. These comparisons suggest that many lead sources were used in the Warring States period, and that complex exchange behaviour between different states possibly occurred. The Qi and Yan coins show no connection with the Baishoulu data and might have their own lead sources (Figs. 12, 13).

Mixing and recycling must also be considered in this complex system. It is reasonable to assume mixing and recycling were taken place, considering the complex metal circulation system as well as the frequent cultural interactions. However, it is hard to estimate the exact scale of mixing and recycling. To estimate mixing and recycling, Mark Pollard proposed a new method for lead isotope data presentation [31, 48]. This method includes 

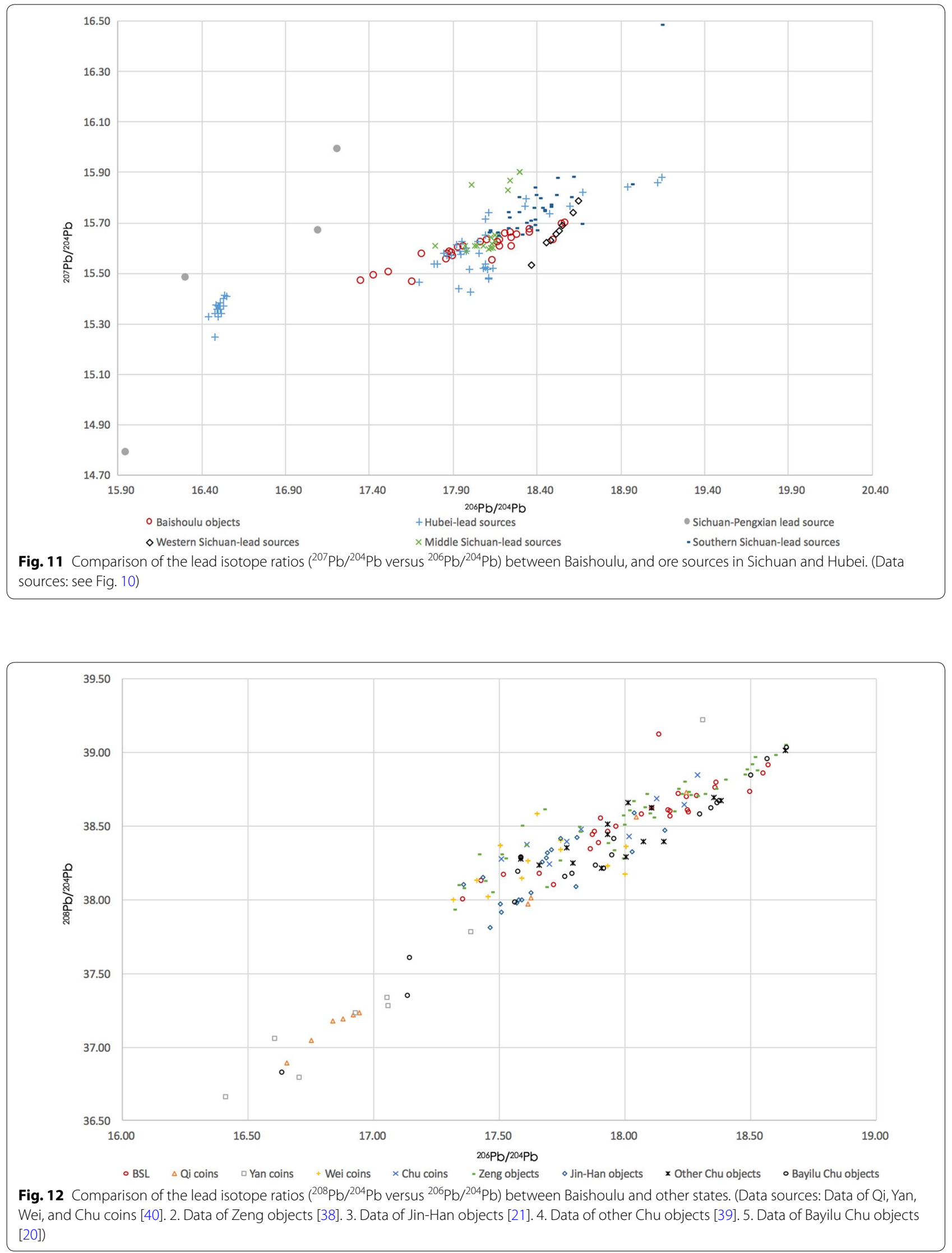


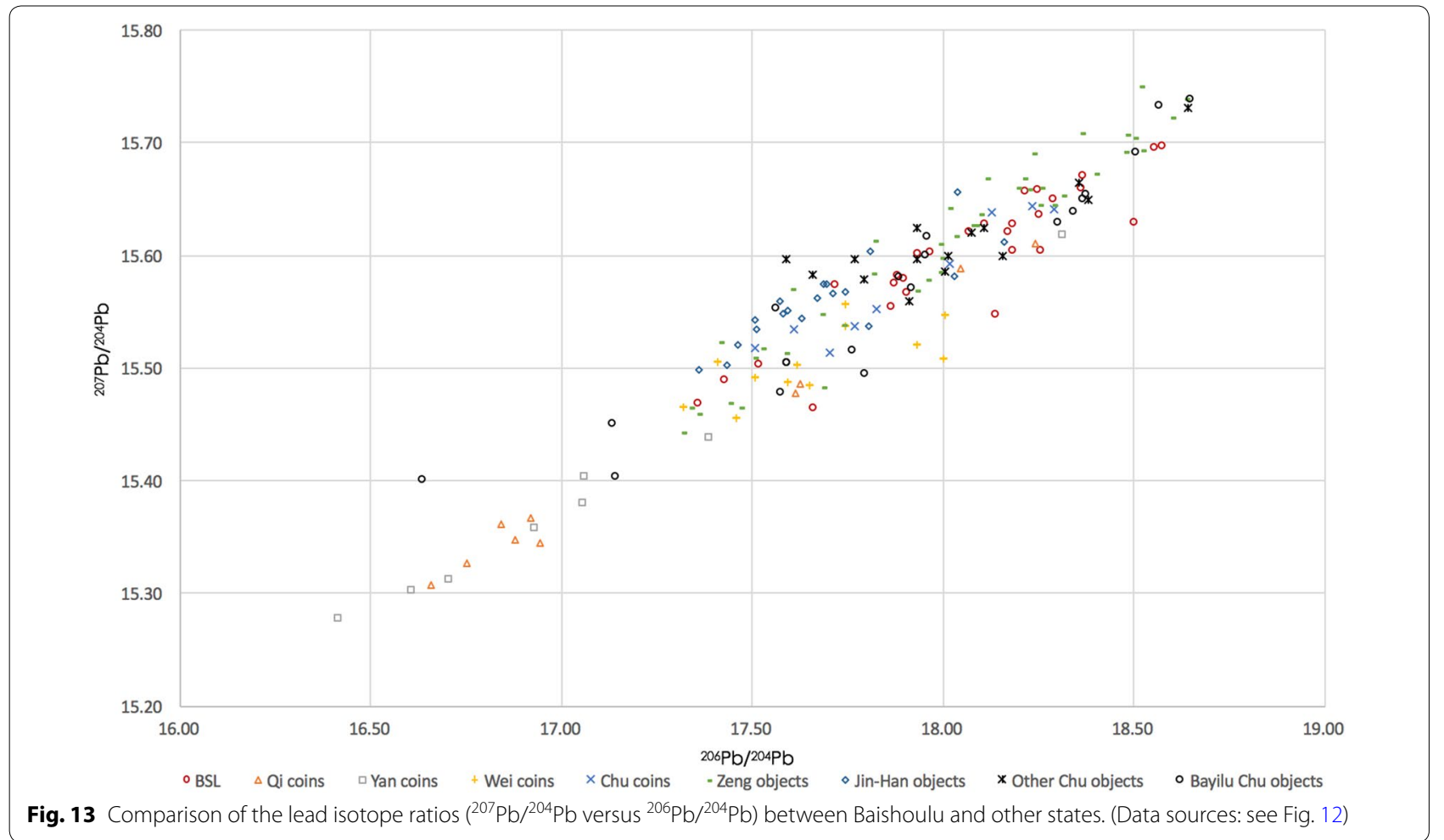

a set of three diagrams which plot the inverse of the lead concentration $(1 / \mathrm{Pb})$ against its lead isotope ratios [48]. It parallels the presentation of strontium isotope data $\left({ }^{87} \mathrm{Sr} /{ }^{86} \mathrm{Sr}\right)$ to detect mixtures of two or more components. If different sources of strontium are mixed, it will show up as a linear mixing line when the isotope ratios are plotted against the inverse strontium concentration. This method has proven useful for discussing the mixing of lead [31]. In this study, three diagrams that include the lead isotope data of Baishoulu and other states aided in estimating the mixing scale. As shown in Fig. 14, all three diagrams show similar results. First, there is no clear mixing line in these diagrams. Second, based on these diagrams, Baishoulu objects, Bayilu Chu objects, and Chu coins show similar isotopic features, but the Bayilu Chu objects covered a larger area. Wei coins overlap with some of the Ba and Shu state data, while the Qi coins and Yan coins were distributed in different areas. Clearly, these new diagrams show the same results as the conventional lead isotope diagrams. Although this does not completely rule out the possibility of mixing [49], the current evidence does not support the idea of large scale mixing in the Warring States period.

The next matter involves the geological origin of these lead sources. This is a complicated issue as there is a lack of quality data on ores, especially from the Warring States period mine pits. Modern lead sources in Sichuan were referred to for comparison. The Sichuan Basin, where the Shu state was located, is surrounded by high-land and mountains. Modern lead sources were distributed all over the Sichuan Basin and surrounding regions. Most of these lead sources are galena. Since the lead sources are rather scattered, this study combines them into 3 types, namely the Western, Middle, and Southern Sichuan. The Pengxian ore source in the Chengdu Plains is the nearest ore source to the centre of the Shu state.

The modern lead ore deposits in Hubei province, where the Zeng and Chu states were located, were also referred to for comparison [50]. Figures 10 and 11, show that the data of Western Sichuan lead sources overlap with some of the Baishoulu objects in both figures. However, most of the lead-source data from Sichuan and Hubei do not suggest any clear connection with Baishoulu objects. Therefore, although some bronzes might have used the lead sources in Western Sichuan, for the most part, the geological origin of their lead sources remains unknown.

\section{Conclusions}

Twenty-eight bronze objects from the Baishoulu cemetery in Chengdu were analysed to study bronze production in the Shu state and its possible relationship with other states. According to the elemental composition, most samples are alloyed with variable tin and lead content. No clear relationship exists between the types and 

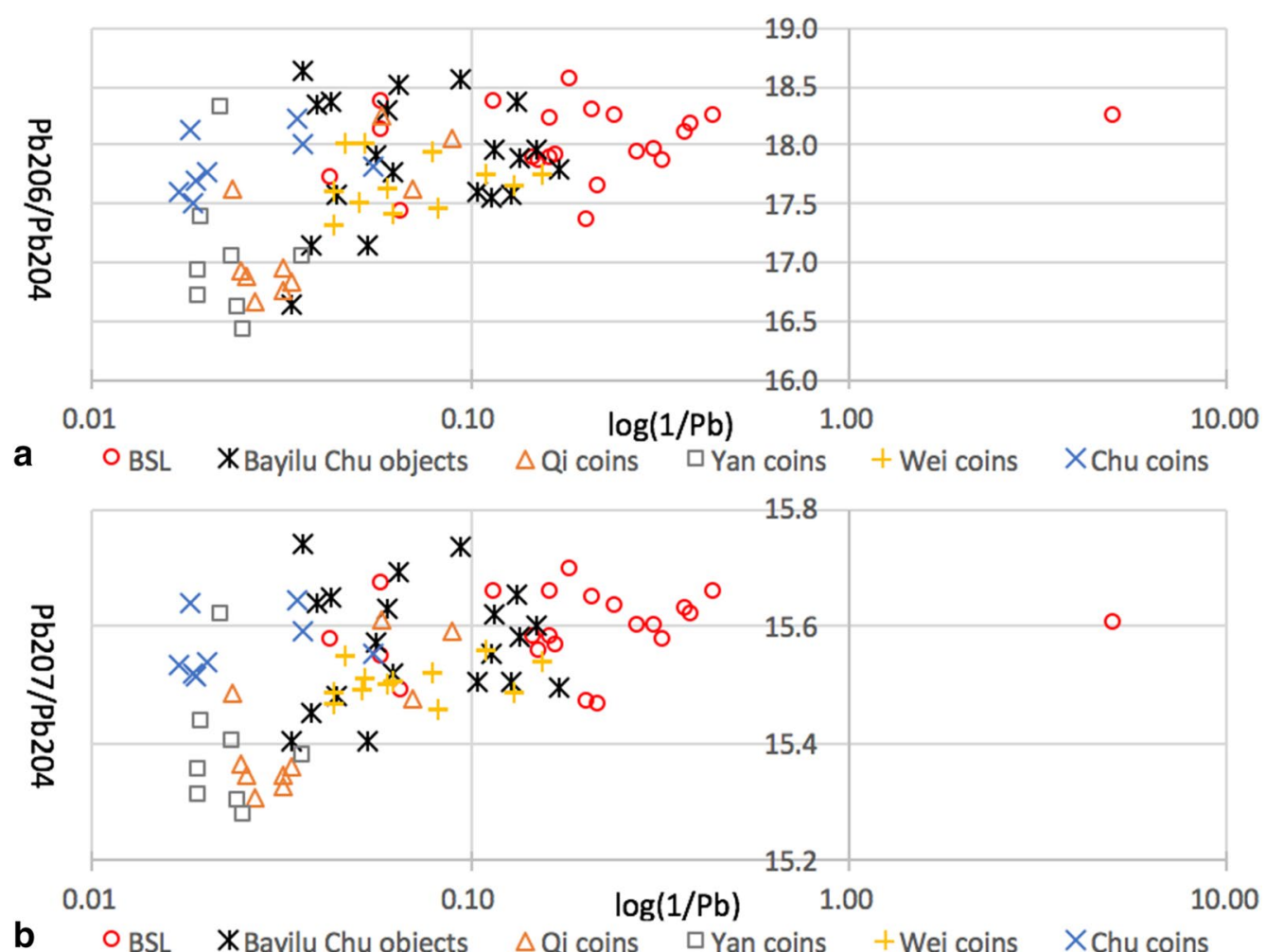

b O BSL $\quad$ Bayilu Chu objects $\triangle$ Qi coins $\square$ Yan coins + Wei coins $\times$ Chu coins

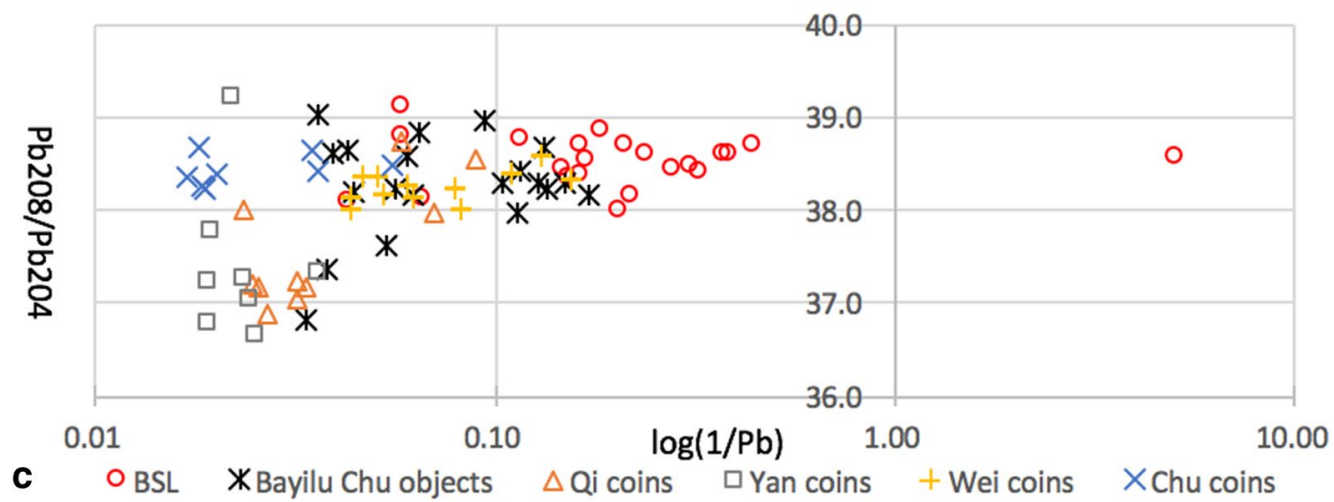

Fig. 14 Lead isotope ratios plotted against $1 / \mathrm{Pb}$ for bronzes of the Warring States period. a ${ }^{206} \mathrm{~Pb} /{ }^{204} \mathrm{~Pb}$ versus $1 / \mathrm{Pb} ; b^{207} \mathrm{~Pb} /{ }^{204} \mathrm{~Pb}$ versus $1 / \mathrm{Pb}$; c ${ }^{208} \mathrm{~Pb} /{ }^{204} \mathrm{~Pb}$ versus $1 / \mathrm{Pb}$

alloying composition. Both casting and cold working and annealing techniques were observed, which provides new information on the techniques used in the Shu state. Comparison with other Shu state sites, as well as with other states, did not lead to definite conclusions.

The lead isotope data suggest that the lead used in Baishoulu comes from multiple sources. The comparison indicates that most Baishoulu samples were made of the same lead sources as those found in the Zeng and Chu states, while the copper and tin sources, according to their different trace elemental patterns, are possibly different. Moreover, some of the Baishoulu artefacts also used the $\mathrm{C}$ type source, which is widely used in the Central Plains and surrounding regions. The actual ore sources' circulation might be much more complex than the relationship with the Zeng and Chu states. Moreover, some Shu state bronzes might have used Western Sichuan lead sources. This information will aid in our understanding of the cultural interactions between the states. In the future, with more systematic data from the different states of the Warring States period, it will be possible to build a metal exchange network between 


\section{different states. Such a network will disclose a new pic- ture of the interactions between the fighting states.}

\author{
Abbreviations \\ ICP-AES: Inductively coupled plasma atomic emission spectroscopy; MC-ICP- \\ MS: Multi-collector inductively coupled plasma mass spectrometry; RSD: Rela- \\ tive standard deviation; DL: Detection limit; CP: Copper groups; BSL: Baishoulu \\ cemetery.
}

\section{Acknowledgements}

The authors wish to thank Dr. Yiu-Kang Hsu (Deutsches Bergbau-Museum Bochum) and Dr. Ruiliang Liu (University of Oxford) for their valuable assistances to and comments on this study.

\section{Authors' contributions}

HL performed the data analysis and was a major contributor in writing the manuscript. JF helped in writing the manuscript. JC helped in interpreting the data. $Z Z, J T, Y Y, L Y$, and ZZ provided the archaeological context. All authors read and approved the final manuscript.

\section{Funding}

This work has been funded by the China Postdoctoral Science Foundation (No 2019T120832) and the Humanity and Social Science Youth Foundation of the Ministry of Education of China (No.19YJC780001 and No. 17XJC780001).

\section{Availability of data and materials}

All data generated or analysed during this study are included in this published article. The dataset supporting the conclusions of this article is also enclosed.

\section{Competing interests}

The authors declare that they have no competing interests.

\section{Author details}

${ }^{1}$ Archaeomaterials Research Laboratory, Sichuan University, Chengdu 610065, China. ${ }^{2}$ Department of Archaeology, School of History and Culture, Sichuan University, Chengdu 610065, China. ${ }^{3}$ Chengdu Municipal Institute of Cultural Relics and Archaeology, Chengdu 610015, China. ${ }^{4}$ School of Archaeology and Museology, Peking University, Beijing 100871, China.

Received: 30 January 2020 Accepted: 28 June 2020

Published online: 08 July 2020

\section{References}

1. Institute of Archaeology, CASS. Archaeology of China: Western and Eastern Zhou Dynasty. Beijing: Chinese Social Science Press; 2004.

2. He J. Annotation of Zhanguoce. Beijing: Zhonghua Press; 2019.

3. Duan Y. The chronology and space framework of ancient Ba and Shu civilizations. J Histo Litera. 2000;6:8-9.

4. Jiang Z, Wang Y, Zhang Q. Preliminary study on the Pre-Qin culture in the Chengdu Plains. Acta Archaeolo Sini. 2002;1:1-22.

5. Jiang Z, Li M. The trace of ancient kingdom. Chengdu: Bashu Press; 2002.

6. Li B. The development phases of Chinese Bronze Age culture and its regional system. Huaxia Archaeol. 1990;2:82-9.

7. Sun H. Several question about the structure of Chinese Bronze Age culture. Archaeol Resea. 2003;5:939-48.

8. Zhu S. Discovery and Research about Ba style bronze object. Beijing: Science Press; 2015.

9. Dai L. Study on the bronze weapons in Sichuan Basin. Doctoral thesis, Hong Kong: The Chinese University of Hong Kong; 2011.

10. Zhu F. Comprehensive study of Chinese bronze. Shanghai: Press of Shanghai Classics Publishing House; 2009.

11. Zeng Z. Elemental compositions of unearthed Bashu style bronze objects. Sichuan Cult Relics. 1992;3:75-7.

12. Chengdu Municipal Institute of Cultural Relics and Archaeology. Reports on canoe shape coffins burial in Shangyejie of Chengdu. Archaeological Discovery in Chengdu, Beijing: Science Press; 2002.
13. Sichuan Provincial Museum, Xindu Cultural Relic Administration. Wooden chamber tomb in Xindu, Sichuan. Cult Relics. 1981;6:1-12.

14. Xiang M. Archaeological observation on the history of Ba and Shu stateBased on the Ba Shu tombs in Eastern Zhou, Qin, Han period. Doctoral thesis, Changchun: Jilin University; 2017.

15. Scott DA. Metallography and microstructure of ancient and historical metals. Singapore: Tien Wah Press; 1991.

16. Sun S, Han R, Li X. Metal materials microstructures in ancient China. Beijing: Science Press; 2011.

17. Li Y. Study on the hot worked thin bronze objects in Pre-qin period and Han Dynasty. Shanghai: Press of Shanghai Classics Publishing House; 2017.

18. YeX. Study on the carved motif bronze in the Eastern Zhou Dynasty. Archaeology. 1983;2:158-64.

19. Kenoyer JM, Miller HML. Metal technologies of the Indus Valley tradition in Pakistan and western India. In: Pigott VC, editor. The emergence and development of metallurgy. Philadelphia: University Museum; 1999. p. 107-151.

20. Mu D, Luo W, Song G, Qiao B, Wang F. The features as a county of Chu state: Chemical and metallurgical characteristics of the bronze artifacts from the Bayilu site. Archaeol Anthropol Sci. 2019;3:1123-9.

21. Shanxi Provincial Institute of Archaeology, Shanxi Museum, Changzhi Municipal Museum. The Eastern Zhou cemetery in Fenshuiling, Changzhi. Beijing: Cultural Relics Press; 2010.

22. Shandong Provincial Institute of Archaeology. Qi state tombs in Linzi. Beijing: Cultural Relics Press; 2007.

23. Lin Y. Annotation of Zhouli. Beijing: Bibliography and Literature Press; 1985.

24. Barnard N. Bronze casting and bronze alloys in ancient China, Monumenta serica monograph series (14). Canberra: Australian National University and Monumenta Serica; 1961.

25. Su R, Hua J. Chinese ancient metal technique. Jinan: Shandong Science and Technique Press; 1995.

26. He T. Preliminary discussion on Liuji. Collected works of history of science and technology (15). Shanghai: Shanghai Science and Technology Press; 1989.

27. Lu D. New discussion on Liuji. Wenbo. 1999;2:70-4

28. Pernicka E. Gewinnung und Verbreitung der Metalle in prähistorischer Zeit. Jahrbuch des Römisch-Germanischen Zentralmuseums Mainz. 1990;37:21-129.

29. Bray PJ, Pollard AM. A new interpretative approach to the chemistry of copper-alloy objects: Source, recycling and technology. Antiquity. 2012;333:853-67.

30. Pollard AM, Bray PJ, Hommel P, Hsu YK, Liu R, Rawson J. Bronze age metal circulation in China. Antiquity. 2017;357:674-87.

31. Pollard AM, Bray PJ, Cuénod A, Hommel P, Hsu Y, Liu R, Perucchetti L, Pouncett J, Saunders M. Beyond provenance: new approaches to interpreting the chemistry of archaeological copper alloys. Leuven (Belgium): Leuven University Press; 2018.

32. Krause R. Grabfunde auf der Nordstadtterrasse von Singen am Hohentwiel. Stuttgart: Theiss; 1988.

33. Čivilytè A, Duberow E, Pernicka E, Skvortzov K. The new late bronze age hoard find from Kobbelbude (former Eastern Prussia, district Fischhausen) and the first results of its archaeometallurgical investigations. Archaeol Anthropol Sci. 2017;9:755-61.

34. Gale N, Stos-Gale Z. Lead isotope analyses applied to provenance studies. In: Ciliberto E, Spoto G, editors. Modern analytical methods in art and archaeology. Chicago: John Wiley \& Sons Incorporated; 2000.

35. Ling J, Hjärthner-Holdar E, Grandin L, Billström K, Persson P-O. Moving metals or indigenous mining? Provenancing Scandinavian bronze age artefacts by lead isotopes and trace elements. J Archaeol Sci. 2013:12:291-304

36. Baron S, Tămaş CG, Le-Carlier C. How mineralogy and geochemistry can improve the significance of $\mathrm{Pb}$ isotopes in metal provenance studies. Archaeometry. 2014;4:665-80.

37. Cui J, Wu X. The study of lead isotopic archaeology. Beijing: Cultural Relics Press; 2008.

38. Suizhou Municipal Museum. Tomb 2 in Leigudun cemetery, Suizhou. Beijing: Cultural Relics Press; 2008.

39. Wen J, Ling X, Zhao C, Zhang Z, Yao Z, Zong C, Yuan H, Wu Z. Preliminary analysis on lead isotope characteristics in Chu State bronzes in Eastern 
Zhou period unearthed from Liu'an District, Anhui Province. J Northwest Polytech Univ (Nat Sci Edn). 2013;6:1016-20.

40. Jin Z. Lead isotope archaeology in China. Hefei: Press of University of Science and Technology of China; 2008.

41. Zhang C. Study on Zeng state bronze objects. Beijing: Cultural Relics Press; 2009

42. Museum H. The tomb of Zeng duke Yi. Beijing: Cultural Relics Press; 1989.

43. Li H. Study on the mining sites in the middle and lower Yangtze River Basin. Archaeology. 2016:10:81-91.

44. Shi J. Sanxingdui and Bashu culture. Chengdu: Bashu Press; 1993.

45. Bai J. Study on the westwards development of the Chu culture based on archaeological remains in Three Gorges region. Jianghan Archaeol. 2016;1:51-64.

46. Zhang J, Chen J. Lead isotopic study on the Eastern Zhou period bronzes. Southern Cult Relic. 2017;2:94-102.

47. Yu Y, Chen J, Mei J, Chen K, Chang H, Huang F. Several issues on the lead isotopic study of Yejiashan bronzes. Southern Cult Relic. 2016;1:94-102.
48. Pollard AM, Bray PJ. A new method for combining lead isotope and lead abundance data to characterise archaeological copper alloys. Archaeometry. 2015:57:996-1008.

49. Liu R, Pollard AM, Rawson J, Tang X, Bray P, Zhang C. Panlongcheng, Zhengzhou and the movement of metal in early bronze age China. J World Prehist. 2019;32:393-428.

50. Hsu YK, Sabatini BJ. A geochemical characterization of lead ores in China: An isotope database for provenancing archaeological materials. PLoS ONE. 2019;14(4):e0215973. https://doi.org/10.1371/journal.pone.0215973.

\section{Publisher's Note}

Springer Nature remains neutral with regard to jurisdictional claims in published maps and institutional affiliations.

\section{Submit your manuscript to a SpringerOpen ${ }^{\odot}$ journal and benefit from:}

- Convenient online submission

- Rigorous peer review

- Open access: articles freely available online

- High visibility within the field

- Retaining the copyright to your article

Submit your next manuscript at $\boldsymbol{\nabla}$ springeropen.com 